\title{
Instrumentos de rendición de cuentas impulsados por los medios de comunicación: percepción de los periodistas y ciudadanos españoles
}

\author{
In-house media accountability instruments: Spanish journalists' \\ and citizens' perceptions
}

\author{
Ramon, X., Mauri-Ríos, M. y Díaz-Campo, J. ${ }^{1}$ \\ Recibido: 10-09-2019 - Aceptado: 24-01-2020 \\ DOI: https://doi.org/10.26441/RC19.1-2020-A13
}

\begin{abstract}
RESUMEN: En un contexto caracterizado por transformaciones estructurales y la crisis de credibilidad del periodismo, la rendición de cuentas de los medios adquiere una importancia central. Focalizándose en el contexto español, este artículo examina las percepciones de los periodistas y los ciudadanos sobre los mecanismos de accountability impulsados por los medios. Para ello se administró una encuesta online a periodistas, se celebraron seis grupos de discusión con ciudadanos y se realizaron 19 entrevistas en profundidad con expertos y representantes de asociaciones profesionales. Los resultados revelan la modesta evaluación que los periodistas hacen de estos instrumentos. Desde la perspectiva ciudadana, se subraya la falta de visibilidad y relativa desconfianza respecto estos mecanismos. Con el objetivo de incentivar la reflexión y la posterior toma de decisiones, se ha diseñado una plataforma open access que permite evaluar si los medios disponen de estos instrumentos clave para fomentar la transparencia, la autorregulación y la participación.
\end{abstract}

Palabras clave: instrumentos de rendición de cuentas; medios de comunicación; España; ética; periodistas; ciudadanos.

ABSTRACT: In a context characterized by structural transformations and the credibility crisis of journalism, media accountability is of outmost importance. Focusing on the Spanish context, this article examines journalists' and citizens' perceptions of in-house accountability instruments. To do so, an online survey was administered to Spanish journalists, six citizen focus groups were established and 19 in-depth interviews were conducted with experts and representatives from professional associations. The results reveal that journalists' evaluation of media accountability instruments is modest. From the citizens' perspective, the lack of visibility and relative distrust toward these instruments are highlighted. With the goal of stimulating the debate and decision-making, an open access platform has been built to evaluate if media organizations have developed these fundamental instruments to promote transparency, self-regulation and participation.

Keywords: media accountability instruments; media; Spain; ethics; journalists; citizens.

\footnotetext{
${ }^{1}$ Xavier Ramon es Doctor en Comunicación y profesor del Departamento de Comunicación de la Universitat Pompeu Fabra. Su investigación y docencia se centran principalmente en los ámbitos de la comunicación deportiva, la ética periodística, la rendición de cuentas y los estudios olímpicos. xavier.ramon@upf.edu, http://orcid.org/00000002-4478-5626

Marcel Mauri-Ríos Doctor en Periodismo y profesor del Departamento de Comunicación de la Universitat Pompeu Fabra donde imparte asignaturas de ética y deontología periodística. Sus principales líneas de investigación son la historia del periodismo y la deontología periodística, el periodismo de calidad y la rendición de cuentas. marcel. mauri@upf.edu, https://orcid.org/0000-0003-2615-8343

Jesús Díaz-Campo es Doctor en Comunicación por la Universidad Complutense de Madrid y Profesor Titular en la Facultad de Empresa y Comunicación de la Universidad Internacional de La Rioja. Sus principales líneas de investigación se centran en Ética de la Comunicación; Comunicación Política y Redes Sociales; Radio y Televisión. jesus.diaz@unir.net, https://orcid.org/0000-0001-5014-8749
} 


\section{Introducción ${ }^{2}$}

En un contexto mediático caracterizado por transformaciones estructurales, la creciente competencia, el descenso de la inversión publicitaria y la crisis de credibilidad y confianza de los medios de comunicación (Broersma, 2019; Luengo, Maciá y Requejo-Alemán, 2017; Serazio, 2019), los profesionales de la información deben mantener la ética y la orientación a la rendición de cuentas como objetivos fundamentales (Christians, Glasser, Nordenstreng y White, 2009). Preservar los estándares éticos debe erigirse como principio rector en un ecosistema marcado por nuevos retos de primer orden que inciden sobre la calidad informativa. Entre ellos cabe destacar la dramática aceleración de los ciclos informativos (Zelizer, 2018), las crecientes exigencias profesionales (English, 2016), la priorización de las métricas como condicionante en la elaboración y difusión de la información (Ferruci, 2018; Justel, Micó y Ordeix, 2018), y la expansión de prácticas vinculadas a la tablodización (Conboy, 2014), como el clickbait o la desinformación (Allcott y Gentzkow, 2017; Hameleers y van der Meer, 2019; Ramon y Tulloch, 2019).

Pese a encontrarse inmerso en un "torbellino de cambios" (Neveu, 2019, p. 198), el periodismo no es ningún "juego sin reglas" (Fengler, Eberwein, Mazzoleni, Porlezza y Russ-Mohl, 2014). La complejidad del presente escenario requiere que todos los actores del proceso comunicativo -profesionales, organizaciones independientes y ciudadanos- se involucren activamente en la ineludible tarea de fomentar la rendición de cuentas (accountability) de los medios de comunicación. De acuerdo con McQuail (2003, p. 19), la rendición de cuentas ocurre cuando los profesionales "toman responsabilidad por la calidad y las consecuencias de su publicación, se orientan a las audiencias y otros afectados, y responden a sus expectativas y a las de la sociedad en general".

La rendición de cuentas se relaciona estrechamente con el concepto de responsabilidad (McQuail, 1997). Como señala Plaisance (2000, p. 260), "rendir cuentas es de hecho ser responsable". Hodges subrayó en su trabajo Defining press responsibility que "no podemos exigir razonablemente que la prensa rinda cuentas o mejore su rendimiento hasta que no determinemos de qué es responsable la prensa" (1986, pp. 14-15).

Según Haydon (1978, p. 57) la responsabilidad "es un requisito que incumbe a cualquier persona simplemente en virtud de ser un actor en el mundo". De acuerdo con su papel esencial en la construcción de la agenda pública y la transmisión de información y valores en las sociedades democráticas (Christians et al., 2009; Singer, 2013), los medios de comunicación y los profesionales que trabajan en ellos deben actuar responsablemente, cumpliendo una serie de obligaciones y compromisos adquiridos para desarrollar su función social de forma adecuada. Dado que "tanto la actividad correcta de los medios como sobretodo la incorrecta tienen fuertes repercusiones en el resto de subsistemas, particularmente en la política, el consumo o los valores formativos" (Aznar y Serrano-Moreno, 2017, p. 183), es de vital importancia que los profesionales respeten los principios deontológicos fundamentales - agrupados en cuatro grandes grupos: verdad, justicia, libertad y responsabilidad, según la clasificación realizada por Alsius (2010) después de analizar los códigos deontológicos más importantes del mundo- en todas las fases del proceso periodístico.

De la responsabilidad emana la rendición de cuentas o accountability, conceptualizada como imperativo que obliga a un actor a responder, explicar y/o justificar su comportamiento ante otros individuos o instituciones "que están afectados por las tareas que desarrollan" (Bovens, Schillemans

\footnotetext{
${ }^{2}$ Este artículo fue presentado en el Working Group de Ética de la Sociedad y Ética de la Comunicación de la International Association of Media and Communication Research (IAMCR) durante el congreso celebrado en Madrid del 7 al 11 de julio de 2019. El texto completo fue seleccionado entre los mejores papers de la edición y propuesto para su publicación al Consejo Editorial de Revista de Comunicación por las Heads del Working Group -Chair Teresa Nicolás Gavilán y Vice-chair Elvira García de Torres.
} 
y Goodin, 2014, p. 6). Específicamente, en el ámbito periodístico la accountability hace referencia a las acciones e iniciativas a través de las cuales se facilita que las organizaciones mediáticas y periodistas cumplan su responsabilidad y rindan cuentas de su trabajo (Hodges, 1986). Pese a que los profesionales de la información pueden rendir cuentas ante diferentes agentes, según la teoría normativa de los medios se espera que los periodistas sitúen como prioritaria la rendición de cuentas hacia los ciudadanos (Harro-Loit, 2015; Traber, 1997).

Como señala Plaisance (2000, p. 259), la accountability "desempeña un papel crítico en el funcionamiento general de los medios". La rendición de cuentas persigue "proteger y promover la libertad de expresión", "prevenir o limitar el daño que los medios puedan causar" y "promover beneficios positivos para la sociedad" (McQuail, 1997, p. 525). También contribuye al proceso de "monitorizar, controlar, criticar y analizar la calidad de la información periodística" (Ramon, Mauri-Ríos y Alcalá-Anguiano, 2016, p. 102). La rendición de cuentas de los medios debe ser fomentada tanto por las mismas empresas periodísticas como por otros actores involucrados en el proceso comunicativo, en base a tres dimensiones clave -transparencia, autorregulación y participación de la audiencia- (Ramon, Mauri-Ríos y Alcalá-Anguiano, 2016).

En primer lugar, como "elemento coadyuvante en la mejora del periodismo de calidad" (Campos-Domínguez y Redondo-García, 2015, p.193), se entiende por transparencia la difusión pública de información corporativa (principios, composición y estructura organizativa, situación económica) y la explicación de los procesos editoriales (Diakopoulos y Koliska, 2017). Comunicar las decisiones estratégicas que subyacen a la producción de contenidos es esencial en el actual "contexto fluido y comercialmente volátil" (Hutchins y Boyle, 2017, p. 49). En segunda instancia, la autorregulación se refiere a los códigos de conducta y otros mecanismos creados por los medios para garantizar la realización de una tarea periodística responsable (Fengler et al., 2014). Finalmente, la participación incluye aquellas iniciativas e instrumentos que fomentan la relación directa con las audiencias para facilitar su participación activa en la creación, revisión y crítica de la información (Eberwein et al., 2011). Manifestando sus pensamientos, valores y expectativas, las audiencias pueden jugar un papel transformativo, corresponsabilizándose de la actividad de rendir cuentas (Culver, 2017).

Estas tres dimensiones se canalizan a través de un amplio abanico de instrumentos de rendición de cuentas (media acountability instruments), impulsados con el profundo convencimiento que "si el periodismo no se autorregula, perderá su credibilidad y su habilidad para promover la democracia" (Ferruci, 2019, p. 290). Bertrand (2018) se refiere a ellos como aquellos mecanismos sin intervención estatal -es decir, no controlados por los gobiernos e impulsados por las empresas, periodistas, organizaciones y ciudadanos (Eberwein et al., 2011)- cuya finalidad es velar por la responsabilidad de los medios y la calidad del producto informativo resultante.

\section{Estado de la cuestión}

\subsection{Investigación sobre los instrumentos internos de accountability}

La investigación académica sobre los instrumentos de rendición de cuentas ha adquirido una relevancia notable en los últimos años. Más allá de los estudios centrados en mecanismos creados fuera de las empresas periodísticas, como los consejos de la información (Almiron, Narberhaus y Mauri-Ríos, 2016; van der Wurff y Schönbach, 2014; Mauri-Ríos, Rodríguez-Martínez, Figueras-Maz y Fedele, 2018), la mayoría de los estudios académicos sobre los instrumentos de rendición de cuentas se han centrado en examinar herramientas internas como los códigos éticos y los libros de estilo (Alsius, 1999; Aznar, 1999; Díaz-Campo y Segado-Boj, 2015; Himelboim y Limor, 2011; Roberts, 2012; Wilkins y Brenner, 2004). 
Estudios previos han señalado de forma extensiva las características generales de las cartas al director como un instrumento clásico para fomentar la participación del público (Raeymaeckers, 2005; Torres da Silva, 2012), además de resaltar la problemática legitimación de las cuatro reglas -relevancia, entretenimiento, brevedad y uniformidad- que influyen en su selección restringiendo frecuentemente la diversidad de voces (Wahl-Jorgensen, 2002). El potencial "aún no explotado plenamente" (Fengler, 2012, p. 827) de la crítica de medios también se ha radiografiado. Los medios cubren la tarea periodística de forma superficial (Alsius, Rodríguez-Martínez and Mauri-Ríos, 2018) y el riesgo de "introducir de forma intencionada o inintencionada un ángulo positivo" (Spiller, Degen, Kronewald, y Guertler, 2016, p. 155) en la cobertura es frecuente.

Una parte significativa de la literatura académica se ha focalizado en el valor y funciones del defensor del lector, que incluyen gestionar "las quejas, cuestiones o puntualizaciones sobre el contenido" (van Dalen y Deuze, 2006, p. 461), "abrir una ventana al funcionamiento interno de las organizaciones mediáticas" (Mayes, 2004, p. 69), y proporcionar "sugerencias sobre como las prácticas se podrían modificar y quien podría hacerlo" (Nolan y Majoribanks, 2011, p. 13). Pese a la expansión de los blogs del defensor del lector en la última década, investigaciones recientes han señalado como esta figura está desapareciendo a un ritmo acelerado. Grandes organizaciones como The New York Times, The Washington Post y, más recientemente, ESPN, han eliminado este rol bajo la premisa que ya no resulta útil (Ferruci, 2019). Estas empresas sostienen que una "multitud de vigilantes" puede proporcionar un escrutinio continuo y un feedback en tiempo real a través de las redes sociales (Ramon, Billings y Rojas-Torrijos, 2019). Sin embargo, la capacidad de los defensores del lector para actuar como un agente neutral y navegar el alud de comentarios y reclamaciones no debe ser subestimada.

Los instrumentos de rendición de cuentas han experimentado una evolución dramática en el entorno digital (Fengler et al., 2014), que permite nuevas formas de fomentar la transparencia, la autorregulación y la supervisión de la calidad informativa en que la participación activa de los usuarios (Eberwein et al., 2011) juega un papel decisivo. En este nuevo escenario, los medios han adaptado sus instrumentos internos y han creado nuevos mecanismos online, como los blogs editoriales que ahondan en los procesos productivos (Spiller et al., 2016), páginas de Facebook en que "los editores y periodistas explican a los lectores sobre su trabajo" (Bjerke, 2018, p. 184) y otros mecanismos de transparencia corporativa (Campos-Domínguez y Redondo-García, 2015). Como Fengler et al. (2014, p. 272) señalan, estas prácticas "pueden cultivar un conocimiento más profundo de los medios entre el público", contribuyendo así a "cultivar la educación mediática de la audiencia" (van der Wurff y Schönbach, 2014, p. 123).

Tabla 1. Instrumentos de accountability impulsados por los medios, según su dimensión: transparencia, autorregulación o participación

\begin{tabular}{|l|l|}
\hline \multicolumn{1}{|c}{ Dimensión } & Instrumentos de rendición de cuentas \\
\hline \multirow{3}{*}{ Tutonsparencia } & Blogs editoriales \\
\cline { 2 - 2 } & Páginas con información corporativa en las webs de los medios \\
\hline Participación de los usuarios & Defensores del lector \\
\cline { 2 - 2 } & Blogs en línea del defensor del lector \\
\cline { 2 - 2 } & Libros de estilo \\
\hline & Crítica del periodismo en secciones o espacios sobre medios \\
\hline & Comentarios de los usuarios en las noticias publicadas \\
\hline & Comentarios de los usuarios en las redes sociales \\
\hline & Botones de corrección de errores \\
\hline & Chats y encuentros digitales con los lectores \\
\hline & Contribuciones de los usuarios en la creación y revisión de los contenidos \\
\hline
\end{tabular}

Fuente: Elaboración propia 
Las empresas también han desarrollado herramientas para reportar errores (Karlsson, Clerwall y Nord, 2017) y permitir la crítica a través de los comentarios, correo electrónico, chats y publicaciones en las redes sociales (Craft, Vos y Wolfgang, 2016). Como argumenta Joseph (2011, p. 711), la transformación del consumidor pasivo a activo "ha abierto nuevas oportunidades para mantener la rendición de cuentas en el periodismo contemporáneo".

\subsection{La percepción profesional sobre los instrumentos de rendición de cuentas in- ternos}

En un estudio pionero, Fengler et al. (2014) realizaron una encuesta comparativa con 1762 periodistas de 14 países diferentes (Alemania, Austria, España, Estonia, Finlandia, Francia, Holanda, Italia, Jordania, Polonia, Reino Unido, Rumanía, Suiza y Túnez) para descubrir las percepciones de los profesionales sobre los instrumentos de rendición de cuentas. El proyecto Media Accountability and Transparency in Europe (MediaAcT) reveló que los periodistas europeos consideran a los libros de estilo como los instrumentos tradicionales creados por los medios de comunicación que tienen la mayor influencia en su práctica profesional (3,74 sobre 5 puntos), seguidos de la crítica mediática $(2,73)$ y los defensores del lector $(2,32)$. En referencia a los instrumentos innovadores, los periodistas europeos valoraron a los comentarios de los usuarios $(2,84)$ por encima de la crítica en redes sociales $(2,61)$ y los blogs editoriales $(2,28)$.

España es uno de los países que forman parte del modelo Mediterráneo o Pluralista Polarizado (Hallin y Mancini, 2004) que presenta un abanico más extenso de instrumentos de rendición de cuentas tradicionales e innovadores (Mauri-Ríos, Rodríguez-Martínez y Alsius, 2018; Rodríguez-Martínez, López-Meri, Merino-Arribas, y Mauri-Ríos, 2017; Suárez-Villegas, Zuberogoitia y Gostín, 2019). El país cuenta con una "desarrollada infraestructura de autorregulación que ha evolucionado después del fin del régimen franquista, incluyendo consejos de la información nacionales y regionales y varios defensores tanto en medios escritos como audiovisuales" (Fengler et al., 2015, p. 256). Los resultados en el escenario español revelaron que los instrumentos innovadores han incidido sobre la mentalidad de los periodistas, puesto que los comentarios $(3,19)$ y la crítica en redes sociales $(3,11)$ fueron evaluados de forma más positiva que mecanismos clásicos como los libros de estilo $(2,86)$, la crítica de medios $(2,81)$ y los defensores $(2,80)$.

Pese a su impacto y novedad, dicha encuesta se realizó entre 2011 y 2012. Por consiguiente, es necesario obtener resultados recientes para identificar los patrones de continuidad y cambio en referencia a la evaluación y opiniones de los periodistas españoles respecto los instrumentos de rendición de cuentas internos. Además, este estudio es el primero en investigar el conocimiento, expectativas y uso de estos instrumentos por parte de los ciudadanos españoles. Este estudio quiere ahondar en si los ciudadanos son conocedores de la existencia de los instrumentos de rendición de cuentas y de qué forma se relacionan con dichas herramientas. Comparar las visiones de ambos agentes -periodistas y audiencias- es esencial para avanzar la investigación en este campo de estudio.

\section{Metodología}

Como parte de un proyecto de investigación competitivo sobre rendición de cuentas de los medios, este estudio tiene dos objetivos fundamentales: examinar la percepción de los periodistas españoles sobre la efectividad de los instrumentos de rendición de cuentas internos (O1) y analizar el conocimiento y comprensión de estos mecanismos por parte de los ciudadanos $(\mathrm{O} 2)$. Para responder a estos objetivos se apostó por la triangulación de métodos. 
En primer lugar, se administró una encuesta online a los periodistas españoles. Siguiendo los criterios señalados por Weischenberg, Malik y Scholl (2006, p. 227)-posteriormente empleados por el proyecto MediaAcT- los encuestados se seleccionaron en base al criterio de ser actores profesionales con una ocupación a tiempo completo o principalmente, y que se dedicaran la publicación de contenidos informativos (Fengler et al., 2015). Al contrario que otros países como Francia, Alemania, Finlandia o Suiza, en el conjunto de España no existen datos oficiales de la demografía de los profesionales del periodismo, ni tampoco un directorio o censo del colectivo (Fengler et al., 2015; Rodríguez-Martínez, Mauri-Ríos y Fedele, 2017). Dada esta limitación estructural, en el marco del proyecto MediaAcT se consideró en base a tres criterios -número de periodistas miembros de asociaciones profesionales, los diferentes tipos de medio y el número aproximado de periodistas por región-que la población estimada de periodistas en España era de 25.000 profesionales. Para abordar con garantías a los profesionales españoles se consideró como válida una sub-muestra de como mínimo 100 participantes (Eberwein et al., 2014, p. 72). La muestra final encuestada se compuso de 123 periodistas (Fengler et al., 2015, p. 24).

Para obtener un número suficiente de respuestas, se buscó la colaboración de instituciones profesionales como la Federación de Asociaciones de Periodistas de España (FAPE), el Colegio de Periodistas de Cataluña y la Asociación de la Prensa de Madrid (APM). El cuestionario se administró a través de la plataforma SurveyMonkey durante el período de tres meses (17 de octubre de 2017 - 17 de enero de 2018). El total de respuestas obtenidas fue de $228(\mathrm{~N}=228)$. De los participantes, $52,2 \%(\mathrm{n}=119)$ fueron mujeres y 47,8\% $(\mathrm{n}=109)$ hombres. La mayoría de los encuestados $(71,1 \%)$ cursó un programa universitario sobre periodismo; $24,1 \%$ de los periodistas trabajaban para medios impresos (periódico, publicación semanal o revista), 29,0\% para emisoras de radio, 26,0\% para cadenas de televisión, 9,2\% para medios online, 9,2\% para agencias informativas y 7,9\% son autónomos (freelance). Los datos fueron analizados empleando el programa IBM Statistical Package for the Social Sciences (SPSS). Para identificar correlaciones estadísticamente válidas, se empleó el coeficiente de correlación de Kendall Tau (Kendall y Gibbons, 1990).

Los resultados de la encuesta se triangularon con la información cualitativa proporcionada por los grupos de discusión con ciudadanos (Bryman, 2016), que se realizaron para obtener una radiografía profunda sobre su conocimiento de los instrumentos de rendición de cuentas y cómo perciben su impacto sobre el rendimiento profesional. Entre abril y mayo de 2018 se celebraron un total de 6 grupos de discusión en diferentes ciudades españolas (Barcelona, Castelló, Madrid, Sevilla, Mondragón y Santiago de Compostela), con 38 participantes en total. De todos los participantes, 58\% fueron mujeres $(n=22)$ y el $42 \%$ fueron hombres $(n=16)$.

Finalmente, para reforzar y contrastar los datos obtenidos a través de las técnicas mencionadas, se llevaron a cabo 19 entrevistas en profundidad (King, 2010) con expertos y miembros de entes de autorregulación y asociaciones profesionales en España. Los entrevistados se seleccionaron en base a criterios estratégicos como su relevancia, experiencia y conocimiento de la ética periodística en el escenario español. Las entrevistas presenciales se realizaron entre abril y junio de 2018, siendo grabadas en audio para su transcripción posterior. Los extractos seleccionados ofrecen matices que complementan las visiones de los periodistas y ciudadanos, facilitando la discusión de los resultados obtenidos. 
Tabla 2. Entrevistas realizadas para el estudio

\begin{tabular}{|l|l|}
\hline Entrevistado/a & \multicolumn{1}{|c|}{ Posición / Cargo } \\
\hline Salvador Alsius & Vice-presidente del Consejo del Audiovisual de Cataluña (CAC) \\
\hline Hugo Aznar & Miembro de la Comisión de Quejas y Deontología de la FAPE \\
\hline Neus Bonet & Decana del Colegio de Periodistas de Cataluña \\
\hline Txuskan Coterón & Decano del Colegio Vasco de Periodistas \\
\hline Carmen Fernández & Consejera del Consejo Audiovisual de Andalucía \\
\hline María José Gómez-Biedma & Periodista y productor de Canal Sur \\
\hline Elsa González & Expresidente de la Federación de Asociaciones de Periodistas de España (FAPE) \\
\hline Roger Jiménez & Presidente del Consejo de la Información de Cataluña \\
\hline Arturo Maneiro & Presidente de la Asociación de Periodistas de Galicia \\
\hline Antonio Manfredi & Director de Radio Televisión de Andalucía (RTVA) en Huelva \\
\hline Lorena Mejías & Miembro de la Junta de Gobierno del Colegio Profesional de Periodistas de Anda- \\
\hline lucía
\end{tabular}

Fuente: Elaboración propia

\section{Resultados}

\subsection{Percepción de los periodistas sobre los instrumentos de rendición de cuentas}

Las respuestas de los periodistas españoles sobre la efectividad de los instrumentos internos de rendición de cuentas se puntuaron usando una escala del 0 (Nada efectivo) a 10 (Altamente efectivo). Los resultados revelan que la percepción que los periodistas españoles encuestados tienen sobre su efectividad es limitada, si bien la mayoría de estos mecanismos reciben una valoración que supera el 5 sobre 10. De entre todos los instrumentos, los libros de estilo obtienen una puntuación más alta $(5,82)$. La tradición de esta herramienta en España, su arraigo y su implantación en muchos medios de comunicación contribuye a explicar este dato, como se indicará en el apartado de discusión. El libro de estilo es seguido por dos instrumentos de implementación mucho más reciente: el apartado en la web con información corporativa $(5,50)$ y los chats y encuentros digitales con lectores $(5,43)$.

Este hecho indica que los periodistas consideran que los mecanismos online son efectivos para ahondar en las tres dimensiones clave de la accountability (transparencia, autorregulación y la participación del público). A estos dos instrumentos se le suman los comentarios de los usuarios en las redes sociales y los comentarios de los usuarios en las noticias publicadas en la web del medio. Con una valoración un poco más baja (5,32 y 5,00, respectivamente), también superan la media.

Otro instrumento que aprueba en valoración de eficacia, con un 5,35, es el defensor del lector o de la audiencia, un mecanismo que también cuenta con un una larga tradición y arraigo en los medios españoles. Estas características también son compartidas con las cartas al director, que obtienen un 5,12 de valoración. Los blogs de los defensores del lector también superan el aprobado, aunque de forma muy ajustada $(5,09)$. Finalmente, entre otros instrumentos de accountability, la crítica del periodismo en las secciones de comunicación y medios registra una puntuación de 5,18. En contraste, los blogs editoriales no llegan al aprobado $(4,61)$. Este resultado es similar al obtenido por los botones de corrección de errores $(4,67)$. 
Tabla 3. Evaluación de los instrumentos internos de accountability por parte de los periodistas españoles

\begin{tabular}{|l|c|}
\hline Instrumentos de rendición de cuentas & $\begin{array}{c}\text { Puntuación } \\
\text { media }\end{array}$ \\
\hline Libros de estilo & 5,82 \\
\hline Páginas con información corporativa en las webs de los medios & 5,50 \\
\hline Chats y encuentros digitales con los lectores & 5,43 \\
\hline Defensores del lector & 5,35 \\
\hline Comentarios de los usuarios en las redes sociales & 5,32 \\
\hline Crítica del periodismo en secciones o espacios sobre medios & 5,18 \\
\hline Cartas al director & 5,12 \\
\hline Blogs en línea del defensor del lector & 5,09 \\
\hline Comentarios de los usuarios en las noticias publicadas & 5,00 \\
\hline Botones de corrección de errores & 4,67 \\
\hline Blogs editoriales & 4,61 \\
\hline Contribuciones de los usuarios en la creación y revisión de los contenidos & 3,72 \\
\hline
\end{tabular}

Fuente: Elaboración propia

Tabla 4. Evaluación de los instrumentos internos de accountability por tipo de medio donde trabajan los periodistas encuestados

\begin{tabular}{|c|c|c|c|c|c|c|c|c|c|c|}
\hline $\begin{array}{l}\text { Instrumentos } \\
\text { de rendición de } \\
\text { cuentas }\end{array}$ & Diario & Semanario & Revista & $\begin{array}{c}\text { Radio } \\
\text { pública }\end{array}$ & $\begin{array}{c}\text { Radio } \\
\text { privada }\end{array}$ & $\begin{array}{c}\text { Televisión } \\
\text { pública }\end{array}$ & $\begin{array}{l}\text { Televisión } \\
\text { privada }\end{array}$ & $\begin{array}{l}\text { Medio } \\
\text { digital }\end{array}$ & $\begin{array}{c}\text { Agencia } \\
\text { de } \\
\text { noticias }\end{array}$ & Freelance \\
\hline Libros de estilo & 6,21 & 7,80 & 7,38 & 6,02 & 4,72 & 5,58 & 4,67 & 6,00 & 6,38 & 4,94 \\
\hline $\begin{array}{l}\text { Defensores del } \\
\text { lector }\end{array}$ & 5,79 & 5,00 & 5,25 & 6,05 & 5,16 & 5,05 & 4,67 & 4,71 & 5,24 & 4,94 \\
\hline $\begin{array}{l}\text { Blogs en línea } \\
\text { del defensor del } \\
\text { lector }\end{array}$ & 5,60 & 5,40 & 5,38 & 5,66 & 4,44 & 4,89 & 4,33 & 5,00 & 4,81 & 4,50 \\
\hline Blogs editoriales & 4,95 & 3,40 & 5,38 & 5,37 & 3,84 & 4,18 & 3,33 & 4,52 & 4,90 & 4,44 \\
\hline $\begin{array}{l}\text { Crítica en } \\
\text { secciones o } \\
\text { espacios sobre } \\
\text { medios }\end{array}$ & 4,98 & 3,20 & 6,25 & 5,85 & 4,72 & 4,86 & 3,56 & 5,57 & 5,62 & 5,28 \\
\hline $\begin{array}{l}\text { Comentarios de } \\
\text { los usuarios en } \\
\text { las redes sociales }\end{array}$ & 4,62 & 6,40 & 5,63 & 5,27 & 5,68 & 4,68 & 5,22 & 4,62 & 4,62 & 5,06 \\
\hline $\begin{array}{l}\text { Comentarios } \\
\text { de los usuarios } \\
\text { en las noticias } \\
\text { publicadas }\end{array}$ & 4,81 & 6,40 & 5,25 & 5,51 & 5,92 & 5,37 & 5,11 & 5,43 & 5,10 & 5,11 \\
\hline Cartas al director & 5,55 & 6,40 & 6,00 & 5,48 & 5,44 & 4,24 & 5,33 & 3,86 & 5,05 & 5,50 \\
\hline $\begin{array}{l}\text { Chats y } \\
\text { encuentros } \\
\text { digitales con los } \\
\text { lectores }\end{array}$ & 5,86 & 6,60 & 6,88 & 5,98 & 5,52 & 4,58 & 5,00 & 4,05 & 5,52 & 5,67 \\
\hline $\begin{array}{l}\text { Botones de } \\
\text { corrección de } \\
\text { errores }\end{array}$ & 4,90 & 3,80 & 5,00 & 5,08 & 4,32 & 4,42 & 4,89 & 4,86 & 4,48 & 4,28 \\
\hline $\begin{array}{l}\text { Contribuciones } \\
\text { de los usuarios } \\
\text { en la creación y } \\
\text { revisión }\end{array}$ & 3,26 & 2,20 & 3,88 & 3,98 & 4,12 & 3,63 & 4,33 & 4,29 & 3,33 & 3,67 \\
\hline $\begin{array}{l}\text { Páginas con } \\
\text { información } \\
\text { corporativa }\end{array}$ & 4,83 & 4,60 & 5,38 & 6,48 & 5,17 & 5,18 & 5,56 & 6,14 & 5,57 & 5,44 \\
\hline
\end{tabular}

Fuente: Elaboración propia 


\section{Diferencias entre tipos de medios}

Según la prueba realizada, que utiliza el coeficiente Tau, de Kendall, existe una correlación (con un 95\% de nivel de confianza) entre el tipo de medio en el que trabaja el informante y la valoración de la efectividad de los instrumentos de accountability. De forma general, los encuestados que trabajan en medios impresos valoran más la efectividad de los instrumentos de rendición de cuentas que los profesionales de radio y televisión. Se debe tener en cuenta que los periódicos han jugado un rol clave en la expansión de los instrumentos de accountability tradicionales e innovadores en el escenario español (Mauri-Ríos y Ramon, 2015; Rojas-Torrijos y Ramon, 2017).

Así pues, aquellos trabajadores de diarios, semanarios y revistas valoran especialmente la efectividad de instrumentos como el libro de estilo, el blog del defensor del lector, las cartas al director o los chats y encuentros digitales con los lectores. Por el contrario, quienes desempeñan sus funciones en radios o televisiones valoran menos la efectividad de estos instrumentos. Este último grupo otorga más importancia a mecanismos como la contribución de los usuarios en la creación y revisión de los contenidos. Por lo que respecta a los profesionales de medios digitales, destacan sobre todo la efectividad de la contribución de los usuarios y el apartado en la web del medio con información corporativa.

\section{Los jóvenes periodistas creen más en la efectividad de los instrumentos de rendición de cuentas}

Según la prueba de correlación empleada, es posible afirmar que existe una correlación (con un nivel de confianza del 95\%) entre la edad del informante y su valoración sobre la efectividad de los instrumentos de rendición de cuentas. En general, se puede observar que los jóvenes perciben los instrumentos como más efectivos que los periodistas con más edad (Tabla 5). De forma interesante, el carácter tradicional o innovador de los instrumentos no guarda relación con la valoración que se hace desde los distintos grupos de edad.

El caso más significativo lo encontramos en la valoración del apartado en la web con información corporativa. Mientras los periodistas de entre 45-54 y 55-64 años valoran este mecanismo con 5,12

y 5,44 puntos de mediana, respectivamente, los profesionales de 19 a 24 años lo evalúan con un 7,67. De hecho, éste es claramente el instrumento mejor valorado entre los más jóvenes cosa que puede interpretarse como una mayor preocupación por la transparencia entre los periodistas que empiezan en la profesión.

Se observa que todos los grupos de edad puntúan la contribución de los usuarios en la creación de contenido por debajo del aprobado, pero recibe más apoyo entre los jóvenes de 19-24 años (4,33 de media) que entre los mayores. También es significativa la diferencia de valoración-que decrece con la edad- de la crítica del periodismo en las secciones o espacios de comunicación y medios: de una valoración media de 6,44 entre los periodistas encuestados de 19 a 24 años, a una valoración de 5,06 entre los de 55-64 años.

Finalmente, el último instrumento donde se observa que la edad del informante influye es en el defensor del lector. Sin embargo, en este caso, debe puntualizarse que son los periodistas de 55-64 años los que más efectividad consideran que tiene $(5,62)$, frente a unos jóvenes que no le dan una valoración alta $(4,56)$. 
Tabla 5. Evaluación de los instrumentos internos de accountability según la edad de los periodistas encuestados

\begin{tabular}{|l|c|c|c|c|c|c|}
\hline Instrumentos de rendición de cuentas & $\mathbf{1 9 - 2 4}$ & $\mathbf{2 5 - 3 4}$ & $\mathbf{3 5 - 4 4}$ & $\mathbf{4 5 - 5 4}$ & $\mathbf{5 5 - 6 4}$ & $\mathbf{6 5 +}$ \\
\hline Libros de estilo & 6,00 & 5,74 & 5,76 & 5,81 & 5,94 & 7,5 \\
\hline Defensores del lector & 4,56 & 4,93 & 5,49 & 5,45 & 5,62 & 8,5 \\
\hline Blogs en línea del defensor del lector & 4,89 & 4,53 & 5,29 & 5,34 & 5,12 & 7,5 \\
\hline Blogs editoriales & 4,33 & 4,29 & 4,88 & 4,64 & 4,56 & 5,5 \\
\hline Crítica del periodismo en secciones o espacios sobre medios & 6,44 & 4,74 & 5,39 & 5,17 & 5,06 & 6,5 \\
\hline Comentarios de los usuarios en las redes sociales & 4,78 & 4,36 & 4,89 & 5,81 & 5,09 & 5,0 \\
\hline Comentarios de los usuarios en las noticias publicadas & 5,33 & 5,03 & 5,44 & 5,55 & 5,24 & 4,5 \\
\hline Cartas al director & 4,56 & 4,93 & 5,15 & 5,79 & 4,47 & 6,0 \\
\hline Chats y encuentros digitales con los lectores & 5,11 & 5,03 & 5,68 & 6,00 & 4,76 & 6,0 \\
\hline Botones de corrección de errores & 5,00 & 3,84 & 5,03 & 5,06 & 4,50 & 7,5 \\
\hline Contribuciones de los usuarios en la creación y revisión & 4,33 & 3,07 & 3,97 & 3,79 & 3,97 & 4,5 \\
\hline Páginas con información corporativa & 7,67 & 5,58 & 5,51 & 5,12 & 5,44 & 4,0 \\
\hline
\end{tabular}

Fuente: Elaboración propia

Los recién llegados confian en la rendición de cuentas

Los años de experiencia como periodista también presentan una correlación (con un 99\% de nivel de confianza, según la prueba de correlación aplicada) con la valoración de efectividad de los instrumentos de rendición de cuentas. A menos experiencia laboral, mayor percepción de efectividad de los instrumentos.

Este comportamiento se observa a la perfección con el apartado de información corporativa en las webs de los medios. Los encuestados con menos de un año de experiencia laboral valoran con un 7,5 de media este mecanismo. Este resultado es similar a la puntuación de 7,26 registrado entre los que llevan entre 1 y 5 años de profesión. En cambio, esta valoración va disminuyendo claramente hasta el 5,15 que le otorgan los periodistas con más de 20 años de experiencia laboral.

Tabla 6. Evaluación de los instrumentos internos de accountability según los años de experiencia de los periodistas encuestados

\begin{tabular}{|c|c|c|c|c|c|c|}
\hline Instrumentos de rendición de cuentas & $\begin{array}{l}\text { Menos } \\
\text { de } 1 \text { año }\end{array}$ & $\begin{array}{c}1-5 \\
\text { años }\end{array}$ & $\begin{array}{l}6-10 \\
\text { años }\end{array}$ & $\begin{array}{l}11-15 \\
\text { años }\end{array}$ & $\begin{array}{l}\text { 16-20 } \\
\text { años }\end{array}$ & $\begin{array}{l}\text { Más de } \\
20 \text { años }\end{array}$ \\
\hline Libros de estilo & 6,75 & 6,54 & 5,10 & 5,42 & 5,86 & 5,96 \\
\hline Defensores del lector & 6,00 & 5,58 & 4,10 & 5,17 & 5,70 & 5,58 \\
\hline Blogs en línea del defensor del lector & 6,50 & 5,08 & 4,17 & 4,72 & 5,62 & 5,25 \\
\hline Blogs editoriales & 5,75 & 5,08 & 3,93 & 4,53 & 5,08 & 4,51 \\
\hline Crítica en secciones o espacios sobre medios & 5,75 & 6,00 & 4,23 & 5,86 & 5,16 & 4,99 \\
\hline Comentarios de los usuarios en las redes sociales & 5,50 & 5,13 & 4,07 & 4,36 & 5,19 & 5,39 \\
\hline Comentarios de los usuarios en las noticias publicadas & 5,50 & 6,29 & 4,17 & 5,17 & 5,70 & 5,34 \\
\hline Cartas al director & 5,50 & 5,00 & 4,50 & 5,11 & 5,49 & 5,20 \\
\hline Chats y encuentros digitales con los lectores & 5,25 & 5,50 & 4,63 & 5,44 & 6,16 & 5,39 \\
\hline Botones de corrección de errores & 5,00 & 4,33 & 3,83 & 4,72 & 4,95 & 4,89 \\
\hline Contribuciones de los usuarios en la creación y revisión & 4,00 & 4,75 & 2,50 & 3,25 & 4,05 & 3,88 \\
\hline Páginas con información corporativa & 7,50 & 7,26 & 5,33 & 5,44 & 5,31 & 5,15 \\
\hline
\end{tabular}

Fuente: Elaboración propia 
En otros cuatro instrumentos más vemos como los años de experiencia laboral influyen en la valoración. Así, los periodistas encuestados con menos de 1 año valoran el libro de estilo con un 6,75 mientras que los de más de 20 años de experiencia le dan un 5,96 de media. Un patrón similar se puede observar con el defensor del lector, valorado con un 6 por los de menos de 1 año y con un 5,5 por los de más de 20 años, pasando por un 4,10 por los que llevan entre 6 y 10 años). Los blogs del defensor del lector se puntúan con un 6,50 de media entre los que tienen menos experiencia, dato que contrasta con el 5,25 entre los más veteranos. De forma similar, esta correlación también se observa en los blogs editoriales: se valoran con un 5,75 entre los periodistas encuestados que hace menos de 1 año que ejercen, pero esta puntuación cae al 4,51 entre los que llevan más de 20 años trabajando.

\section{Efectividad y el fomento de la responsabilidad}

En este apartado se comparan las respuestas a la pregunta "¿Cuál es su percepción sobre la efectividad de los siguientes mecanismos, impulsados por los medios de comunicación?" con las que se dieron a " $¿$ Creen que los mecanismos mencionados anteriormente contribuyen a fomentar la responsabilidad, es decir, la calidad informativa, el pluralismo y la transparencia mediática?", divididas entre quienes respondieron de forma positiva $(n=150 ; 65,8 \%$ de la muestra) y negativa $(\mathrm{n}=78 ; 34,2 \%)$. La tabla 7 demuestra que las puntuaciones son mayores en el caso de los que sí creen que los instrumentos son efectivos, para quienes nueve de esos instrumentos fomentan la responsabilidad profesional. Por el contrario, entre los que creen que los instrumentos no son efectivos, únicamente uno de los instrumentos analizados (libro de estilo) consigue ese objetivo.

Hay, no obstante, coincidencias entre unos y otros, ya que en ambos casos el libro de estilo es el instrumento que consigue una mayor puntuación. El defensor del lector y los chats y encuentros digitales figuran igualmente entre los más valorados en ambos casos. Los dos grupos coinciden en considerar la contribución de los usuarios en la creación y revisión de contenidos el mecanismo más efectivo, junto con los blogs editoriales y los botones de corrección de errores.

Tabla 7. Evaluación de los instrumentos internos de accountability de acuerdo a su percepción general sobre estos mecanismos

\begin{tabular}{|l|c|c|}
\multirow{2}{*}{\multicolumn{1}{c|}{ Instrumentos de rendición de cuentas }} & $\begin{array}{c}\text { ¿Cree que los instrumentos de } \\
\text { accountability contribuyen a } \\
\text { fomentar la responsabilidad? }\end{array}$ \\
\cline { 2 - 3 } & Sí & No \\
\hline Libros de estilo & 6,13 & 5,23 \\
\hline Defensores del lector & 5,69 & 4,68 \\
\hline Blogs en línea del defensor del lector & 5,33 & 4,62 \\
\hline Blogs editoriales & 4,80 & 4,24 \\
\hline Crítica en secciones o espacios sobre medios & 5,62 & 4,32 \\
\hline Comentarios de los usuarios en las redes sociales & 5,29 & 4,42 \\
\hline Comentarios de los usuarios en las noticias publicadas & 5,70 & 4,59 \\
\hline Cartas al director & 5,29 & 4,81 \\
\hline Chats y encuentros digitales con los lectores & 5,70 & 4,92 \\
\hline Botones de corrección de errores & 4,99 & 4,06 \\
\hline Contribuciones de los usuarios en la creación y revisión & 4,06 & 3,06 \\
\hline Páginas con información corporativa & 5,91 & 4,71 \\
\hline
\end{tabular}

Fuente: Elaboración propia 


\subsection{La percepción de los ciudadanos sobre los instrumentos de accountability}

En esta sección, nos centramos en analizar el conocimiento y comprensión de los instrumentos de rendición de cuentas por parte de los ciudadanos. Por encima de todo, los ciudadanos resaltaron la necesidad de promover los instrumentos de accountability y contrarrestar su actual falta de visibilidad. Como enfatizó claramente un participante, "claro que importa que tengas un defensor del lector, pero ponlo en la página principal. Si tienes un código ético, ponlo también en la página principal" (GD06-H).

Los libros de estilo se valoraron de forma positiva e incluso considerados "fundamentales" (GD01-H), especialmente para cubrir cuestiones sensibles como el sexismo o el racismo. Un documento ampliamente conocido es el libro de estilo de El Pais, un medio que durante su trayectoria ha dedicado un énfasis remarcable a la rendición de cuentas (Gutiérrez del Álamo, 2015; Seoane y Sueiro, 2004). Dicho esto, hay una cierta falta de confianza entre su efectividad real dentro de los medios de comunicación. Dado que "tú publicas tu código ético y que lo sigues como quieres" (GD06-H), algunos ciudadanos creen que crear estos documentos "es muy sencillo" (GD06-M) pero consideran que hay veces que no se aplican por intereses particulares. Otros argumentan que los ciclos informativos acelerados impuestos sobre los periodistas dificultan la aplicación de estas guías: "Creo que con la inmediatez que existe hoy en día en el mundo del periodismo, el libro de estilo se utiliza cada vez menos [...] el redactor va a destajo, trabajando para acabar la noticia rápidamente antes que el redactor que tiene al lado y no lo usa prácticamente nada" (GD03-H).

La figura del defensor del lector es generalmente desconocida. Algunos ciudadanos cuestionan la validez de este rol, preguntándose sobre si "está condicionado por la ideología de su medio" (GD01-M), mantiene la "distancia" adecuada (GD03-H) o "edulcora las posibles quejas de alguna forma" (GD02-H). Otros participantes incluso creen que este puesto no es necesario en la era digital, debido a que la audiencia actualmente puede comentar las noticias, formular quejas en las redes sociales o producir nuevos contenidos. Claramente, la falta de visibilidad es un problema de primer orden: "No tiene visibilidad, nadie entra allí [...] Hay gente que lo hace, igual que la gente que envía dudas a las RAE [Real Academia Española] pero no es una herramienta de uso masivo por así decirlo" (GD06-M). Los participantes desconocen otras opciones como los blogs editoriales o la crítica en las secciones de medios.

Las actitudes de los ciudadanos sobre las herramientas que promueven la transparencia son ambivalentes. Mientras que algunos participantes creen que estos mecanismos son innecesarios porque "los consumidores ya saben que hay detrás del contenido" (GD01-M), otros insisten que la audiencia tiene el "derecho a saber" (GD03-M). De acuerdo con estos participantes, "hay muchas veces que no conocemos quien está detrás realmente, qué grupos políticos o que poderes económicos hay detrás de un medio" (GD01-M). Por consiguiente, es importante revelar "los anunciantes y los accionistas detrás de las empresas" (GD02-H). La publicación de las cuentas de resultados se interpreta como un acto de transparencia y generó un sentimiento de aprobación general durante los grupos de discusión, pese al contexto de desconfianza hacia el periodismo que reina entre la audiencia.

De acuerdo con los participantes, el contacto visible y accesible a través del cual las audiencias pueden mandar quejas sobre el contenido publicado "está creciendo de forma exponencial" (GD01-H), hecho que puede ayudar a los profesionales del periodismo a realizar su tarea de forma más efectiva. No obstante, los ciudadanos son conscientes que los medios acostumbran a responder a la crítica en las redes sociales de acuerdo con el nivel de interés que haya generado una cierta queja. En relación a este punto, un participante enfatizó: "hasta que no se ven perjudicados por un gran número de personas que se han quejado, no van a reaccionar porque ellos siguen su línea [...] Entonces luego dicen perdón porque les interesa mantener una buena imagen para atraer a lectores" (GD01-M). Para los ciudadanos, la participación de la audiencia en la producción informativa -a través del 
envío de textos o vídeos- es cada vez más frecuente. Los ciudadanos señalan que a veces, una pista enviada por los usuarios "se sigue para investigar algo" (GD03-M).

De forma general, se consideran positivos los comentarios de los usuarios en las noticias. Los ciudadanos perciben que "Internet es un espacio más democrático" (GD04-M) y sienten que es importante que "se abran espacios virtuales de debate" (GD04-M). De acuerdo con ellos, los comentarios pueden tener varias funciones, entre ellas denunciar una situación, proporcionar nueva información y promover el debate. Pese a esto, los ciudadanos son conscientes que muchos comentarios contribuyen poco o no añaden información de valor a la discusión. También advierten que hay muchos comentarios "irrespetuosos" (GD02-M) y ofensivos. De forma interesante, consideran que las cartas al director incluyen ideas más reposadas y profundas y, por tanto, las perciben como más valiosas que los comentarios online. Como expresó un participante, "una carta requiere pensarla, estructurarla y eso ya conlleva un ejercicio de reflexión sobre lo que se está diciendo" (GD01-M).

Los chats y los encuentros digitales con los lectores no son extensamente conocidos ni usados por los participantes. Aquellos que han participado en algunos de estos encuentros reconocen que son interesantes, pero sostienen que tienen una función más lúdica o de entretenimiento que crítica o reflexiva: "de forma habitual, no encuentras mucha profundidad" (GD06-H), argumentó un participante. Finalmente, los botones de corrección de errores son relativamente desconocidos. Los participantes expresaron que "se debería facilitar más el poder corregir errores" (GD01-M), pero destacan que generalmente, "ningún medio español reconoce los fallos que hace" (GD03-M).

\section{Discusión}

Los resultados de la encuesta y los grupos de discusión permiten visualizar las semejanzas y diferencias entre las percepciones de los periodistas y ciudadanos españoles sobre la efectividad de los instrumentos de rendición de cuentas creados desde los medios. La implementación histórica de los libros de estilo en muchas organizaciones, desde periódicos impresos como El País, La Vanguardia o El Mundo hasta radiodifusores públicos como RTVE, TV3, EITB o Canal Sur (Alsius, 1999; Rojas-Torrijos y Ramon, 2017; Zuberogoitia, Bidegain y Gostín, 2019), pueden explicar la preferencia de los periodistas españoles por este instrumento que funciona como "una luz intermitente permanentemente encendida para ir recordando a los profesionales que existen unos principios y unos valores" (Salvador Alsius) y que contribuye a "educar a los ciudadanos" (Neus Bonet).

Los participantes en los grupos de discusión también perciben el valor de los libros de estilo pero sin embargo son escépticos sobre su efectividad real. Un problema central, en palabras de María José Gómez-Biedma, es que los libros de estilo "en muchas ocasiones apenas son utilizados en el trabajo diario" debido, en parte, a las presiones conectadas con la híper-aceleración de los ciclos informativos (Zelizer, 2018). Este factor, combinado con su baja visibilidad y el hecho que "no penalizan su incumplimiento" (Carmen Fernández Morillo) ni "establecen ninguna sanción” (Xose Manuel Pereiro) puede explicar su baja puntuación obtenida en la encuesta $(5,82)$ y la relativa desconfianza mostrada por los ciudadanos en los focus groups. Esta desconfianza no puede disociarse del "desencanto público y el sentimiento generalizado de desdén hacia las instituciones sociales" (Hanitzsch, Van Dalen y Steindl, 2018, p. 7).

Los periodistas consideran algunos mecanismos innovadores (información corporativa en las webs de los medios, chats y encuentros digitales y los comentarios en las redes sociales) como las herramientas más efectivas para promover la rendición de cuentas, reforzando así los resultados obtenidos por Fengler et al. (2014) en su análisis del escenario español en el marco del proyecto MediaAcT. La evaluación de los ciudadanos españoles se asimila a la de los periodistas -particularmente, de aquellos que han accedido recientemente a la profesión y aquellos que desarrollan su 
tarea en medios digitales- sobre el valor de estrategias de transparencia como publicar la información corporativa y los estados financieros en línea. De acuerdo con Nemesio Rodríguez, presidente de la FAPE, los medios españoles son "bastante opacos". Por tanto, sería deseable que los medios "expresaran de forma abierta su línea editorial" y revelasen "de donde procede el dinero que reciben" (Violeta Tena).

Las percepciones de los periodistas y los ciudadanos también conectan en considerar los comentarios (en las webs de los medios y en redes sociales) como forma de "facilitar la libertad de expresión” (Lorena Mejías) y "denunciar malas praxis periodísticas” (María José Gómez-Biedma). De acuerdo con los expertos, ambos grupos - periodistas y ciudadanos- son conscientes que "la crítica es sana y necesaria" (Elsa González) y "que se debe establecer un feedback" (Ramón Zallo). Pese a todo, también consideran que en muchas ocasiones, los comentarios generan ruido en lugar de contribuir al debate sobre la calidad del producto informativo. A la luz de estas percepciones, expertos como Txuskan Coterón y Pepe Soto proponen la introducción de filtros asociados con las tradicionales cartas al director, como por ejemplo el requisito de proporcionar una serie de datos identificativos (Pastor, 2010).

Cuando se evalúan los chats y la participación de la audiencia en la producción informativa, las visiones de los periodistas y ciudadanos difieren. En el primer caso, los periodistas creen que los encuentros digitales son efectivos, pero los ciudadanos no son generalmente conscientes de su existencia o enfatizan su naturaleza lúdica. En el segundo caso, los ciudadanos perciben que las nuevas opciones de participación son cada vez más frecuentes y potencialmente útiles, mientras que los periodistas -independientemente de su edad-creen que la participación de los usuarios en la producción de noticias es un mecanismo de accountability poco efectivo.

Cuando se valora otro instrumento tradicional, los defensores del lector, surgen diferencias notables entre los periodistas y los ciudadanos. El defensor es un mecanismo con una larga trayectoria en España (Alsius et al., 2018; García-Avilés, 2019; Maciá, 2006). De hecho, El País introdujo esta figura en 1985 (Gutiérrez del Álamo, 2015), siendo seguido posteriormente por otros medios como La Vanguardia, La Voz de Galicia, El Punt o RTVE. El prestigio asociado con el defensor explica su percepción positiva entre los profesionales - especialmente entre aquellos de entre 55 y 64 años de edad-, pese a que muy pocas organizaciones disponen actualmente de esta figura. De forma similar a lo sucedido en otros países (Ferruci, 2019), en España esta figura "ha casi desaparecido en los medios por abaratar costes" (Elsa González). Se debe tener en cuenta, tal como Antonio Manfredi señala, que la crisis económica ha llevado al "cierre o reducción de las redacciones" en todo el país. Como enfatiza Violeta Tena, "los mecanismos de rendición de cuentas valen dinero y en la situación en la que estamos ahora mismo, desgraciadamente, los medios no están apostando por esto".

Multitud de medios en todo el mundo también perciben el defensor "ya no es útil frente al feedback en tiempo real proporcionado por las redes sociales" (Ramon, Billings \& Rojas-Torrijos, 2019, p. 28). Es interesante recalcar que los ciudadanos españoles lo perciben de forma similar, creyendo que esta figura es innecesaria en la era digital. También plantean sus inquietudes sobre la independencia de los defensores. Estas percepciones pueden estar influenciadas por la falta de conocimiento de los ciudadanos sobre las características y el valor de esta figura (Mayes, 2004; van Dalen y Deuze, 2006). La escasa visibilidad del defensor del lector -incluso en su forma digital- entre los medios españoles también puede explicar estas percepciones.

Otros instrumentos de accountability como los blogs editoriales y los botones de corrección de errores no son apreciados ni por los periodistas ni por los ciudadanos. Este resultado puede explicarse por el bajo desarrollo de estas herramientas en las redacciones españolas (García-Avilés, 2019; Mauri-Ríos y Ramon, 2015) y, por consiguiente, la falta de reconocimiento de su existencia entre las audiencias. Pese a que "no se pierde ni reputación ni prestigio cuando se aceptan los errores" 
(Roger Jiménez), a los medios españoles "no les interesa estar todo el día disculpándose" (Begoña Zabildea). De acuerdo a los expertos entrevistados, la inclusión de botones de corrección de errores sería "altamente efectiva" dado el escenario informativo actual en que "la velocidad e inmediatez con la que trabajamos provoca baja calidad léxica y de contenido" (Luis Menéndez).

\section{Conclusiones}

Los resultados de esta investigación señalan que los periodistas españoles creen que los instrumentos de rendición de cuentas creados por los medios "promueven la calidad informativa" (Arturo Maneiro). Los periodistas prefieren la accountability a la regulación, teniendo en cuenta que "las leyes siempre limitan" (Rafael de Mendizábal). De acuerdo con Hugo Aznar, los profesionales no deben esperar que estos "mecanismos vayan a cambiar el mapa comunicativo del país de la noche la mañana, pero sí pueden ir fomentando una cultura de mayor responsabilidad". Esto no esconde que la evaluación que los periodistas realizan de estas herramientas es notablemente modesta. Desde la perspectiva ciudadana, la falta clara de visibilidad de muchos instrumentos puede explicar porque mayoritariamente son poco usados o percibidos como inefectivos.

Esta doble "desconexión" de la rendición de cuentas (desde la perspectiva profesional y ciudadana) revela la necesidad de repensar y revitalizar los instrumentos existentes con el fin de contribuir al objetivo de mejorar "los servicios de los medios hacia el público" y restaurar "el prestigio de los medios a los ojos de la población" (Bertrand, 2018, p. 57). Los resultados de este proyecto pueden informar a las empresas comunicativas sobre la necesidad de revisar y actualizar su portafolio de instrumentos para asegurar su efectividad en la práctica periodística. Mejorar la visibilidad de los instrumentos existentes y de aquellos por aparecer es fundamental para incrementar la educación mediática de los ciudadanos y asegurar que se involucren activamente en la tarea de rendir cuentas (Eberwein et al., 2011).

Partiendo de estos resultados y con el objetivo de incentivar la reflexión y la posterior toma de decisiones entre los profesionales, se ha diseñado una plataforma web de acceso abierto ( $h t t p: / /$ mediaaccountability.upf.edu) que permite a los medios evaluar si disponen y emplean dichos instrumentos. Dicha plataforma plantea varias preguntas y propone un sistema de puntuación sobre 15 puntos para determinar si un medio presenta una escasa orientación a la rendición de cuentas ( $0-5$ puntos), favorece la rendición de cuentas (6-10 puntos) o fomenta activamente la rendición de cuentas (11-15 puntos). Esta herramienta open access puede ayudar a la introducción o rediseño de instrumentos de accountability en aras de mejorar la transparencia, autorregulación y participación de los usuarios.

Desde el ámbito académico, esta plataforma también puede contribuir a fomentar los análisis de los medios de comunicación. En el marco de un territorio o región, se puede observar el grado de implantación y la naturaleza de los instrumentos de accountability presentes en una serie de medios e identificar los más utilizados. Esto puede ayudar a identificar tendencias, similitudes, fortalezas y debilidades de los medios sometidos al análisis. 
Imagen 1. Test de autoevaluación de los instrumentos de rendición de cuentas desarrollado por el equipo MediaACES (http://mediaaccountability.upf.edu)

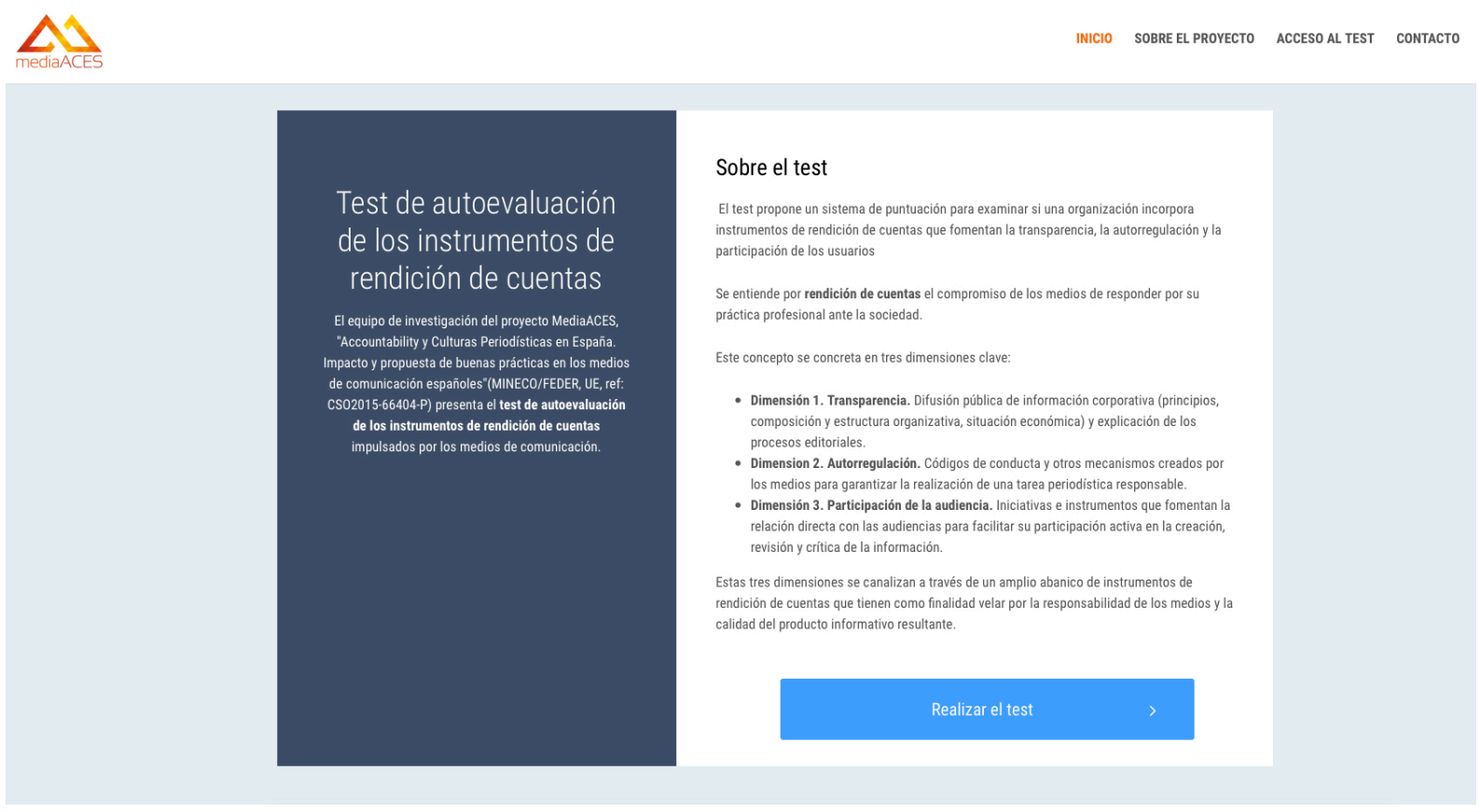

Fuente: Elaboración propia

Más allá de los instrumentos internos, futuras investigaciones deben superar las limitaciones de este estudio para interrogar como los periodistas y ciudadanos perciben la efectividad de mecanismos externos como los códigos éticos, los consejos de la información, los observatorios o los blogs de crítica de medios promovidos por las audiencias (Fengler et al., 2014). Monitorizar cómo ambos grupos evalúan los instrumentos de accountability tradicionales e innovadores creados dentro y fuera de las organizaciones mediáticas se considera esencial para obtener una radiografía más rica y precisa de la evolución de la rendición de cuentas en España y comparar este desarrollo con la situación en otros territorios y culturas periodísticas.

Como señala Schmitz (2015, p. 96), "es necesaria más investigación comparativa para comprender qué está sucediendo en el periodismo hoy en día en diferentes partes del mundo". Resulta especialmente necesaria la realización de nuevas investigaciones que ahonden en la rendición de cuentas en América Latina. Puesto que la "ética periodística permanece como un área de énfasis y preocupación en la región" (Higgins Joyce, Saldaña, Schmitz y Alves, 2017, p. 460), futuros trabajos deben trabajar para discernir de que forma los periodistas y los ciudadanos en múltiples países perciben e interactúan con los instrumentos de accountability en sus respectivos territorios.

\section{Agradecimientos}

Este artículo forma parte del proyecto de investigación MediaACES, 'Accountability y Culturas Periodísticas en España. Impacto y propuesta de buenas prácticas en los medios de comunicación españoles', financiado por el Ministerio de Economía y Competitividad de España y el Fondo Europeo de Desarrollo Regional (MINECO/FEDER, UE, ref: CSO2015-66404-P). Los primeros resultados de este trabajo se presentaron en el grupo 'Ethics of Society and Ethics of Communication' durante el congreso de la International Association for Media and Communication Research (IAMCR) celebrado en Madrid del 7 al 11 de julio de 2019. 


\section{Bibliografía}

Allcott, H., \& Gentzkow, M. (2017). Social Media and Fake News in the 2016 Election. Journal of Economic Perspectives, 31(2), 211-236. https://doi.org/10.1257/jep.31.2.211

Almiron, N., Narberhaus, M., \& Mauri-Ríos, M. (2016). Mapping media accountability in stateless nations: the case of Catalonia. Catalan Journal of Communication \& Cultural Studies, 8(2), 207-225. https://doi.org/ 10.1386/cjcs.8.2.207_1

Alsius, S. (1999). Codis ètics del periodisme televisiu. Barcelona: Pòrtic.

Alsius, S. (Ed.) (2010). The ethical values of journalists. Field research among media professionals in Catalonia. Barcelona: Generalitat de Catalunya.

Alsius, S., Rodríguez-Martínez, R., \& Mauri-Ríos, M. (2018). New formats and old crisis. En T. Eberwein, S. Fengler, \& M. Karmasin (Eds.), The European Handbook of Media Accountability (pp. 243-250). Abingdon, Oxon: Routledge.

Aznar, H. (1999). Ética y periodismo. Barcelona: Paidós.

Aznar, H., \& Serrano-Moreno, J. (2017). Autorregulación de la comunicación: análisis de las cien primeras resoluciones de la Comisión de Arbitraje, Quejas y Deontología de la FAPE. El Profesional de la Información, 26(2), 182-191. https://doi.org/10.3145/epi.2017.mar.04

Bertrand, C. J. (2018). Media ethics and accountability systems. New York: Routledge.

Bjerke, P. (2018). Norway: Journalistic power limits media accountability. En T. Eberwein, S.

Fengler, \& M. Karmasin (Eds.), The European Handbook of Media Accountability (pp. 180-189). Abingdon, Oxon: Routledge.

Bovens, M., Goodin, R.E., \& T. Schillemans (2014). The Oxford handbook of public accountability. Oxford: Oxford University Press.

Broersma, M. (2019). The legitimacy paradox. Journalism, 20(1), 92-94. https://doi. org/10.1177/1464884918806736

Bryman, A. (2016). Social research methods (5 ed.). Oxford: Oxford University Press.

Campos-Domínguez, E., \& Redondo-García, M. (2015). Meta periodismo y transparencia informativa en el periodismo del siglo XXI. Obets. Revista de ciencias sociales, 10(1), 185-209. https://doi.org/10.14198/OBETS2015.10.1.07

Christians, C. G., Glasser, T. L., Nordenstreng, K., \& White, R.A. (2009). Normative theories of the media. Journalism in democratic societies. Urbana: University of Illinois Press.

Conboy, M. (2014). Celebrity journalism - an oxymoron? Forms and functions of a genre. Journalism, 15(2), 171-185. https://doi.org/10.1177/1464884913488722

Craft, S., Vos, T., \& Wolfgang, J. D. (2015). Reader comments as press criticism: Implications for the journalistic field. Journalism, 17(6), 677-693. https://doi.org/10.1177/1464884915579332

Culver, K. B. (2017). Disengaged ethics: Code development and journalism's relationship with "the public". Journalism Practice, 11(4), 477-492. https://doi.org/10.1080/17512786.2015.112 1788

Diakopoulos, N., \& Koliska, M. (2017). Algorithmic transparency in the news media. Digital Journalism, 5(7), 809-828. https://doi.org/10.1080/21670811.2016.1208053 
Díaz-Campo, J., \& Segado-Boj, F. (2015). Journalism ethics in a digital environment: how journalistic codes of ethics have been adapted to the Internet and ICTs in countries around the world. Telematics and Informatics, 32(4), 735-744. https://doi.org/10.1016/j.tele.2015.03.004

Eberwein, T., Fengler, S., Philipp, S., \& Ille, M. (2014). Counting Media Accountability - the Concept and Methodology of the MediaAcT Survey. En S. Fengler, T. Eberwein, G. Mazzoleni, C. Porlezza, \& S. Russ-Mohl (Eds.), Journalists and media accountability. An international study of news people in the digital age (pp: 65-79). Nueva York: Peter Lang.

Eberwein, T., Fengler, S., Lauk, E., \& Leppik-Bork, T. (Eds.) (2011). Mapping media accountability - in Europe and beyond. Colonia: Helbert Von Halem Verlag.

English, P. (2016). Mapping the sports journalism field: Bourdieu and broadsheet newsrooms. Journalism, 17(8), 1001-1017. https://doi.org/10.1177/1464884915576728

Fengler, S. (2012). Holding the news media accountable: a study of media reporters and media critics in the United States. Journalism \& Mass Communication Quarterly, 80(4), 818-832. https://doi.org/10.1177/107769900308000405

Fengler, S., Eberwein, T., Mazzoleni, G., Porlezza, C., \& Russ-Mohl, S. (2014). Journalists and media accountability. An international study of news people in the digital age. Nueva York: Peter Lang.

Fengler, S., Eberwein, T., Alsius, S., Baisnée, O., Bichler, K., Dobek-Ostrowska, B., \& Zambrano, S. (2015). How effective is media self-regulation? Results from a comparative survey on European journalists. European Journal of Communication, 30(3), 249-266. https://doi. org/10.1177/0267323114561009

Ferruci, P. (2018). It is in the numbers: How market orientation impacts journalists' use of news metrics. Journalism, 1-18. https://doi.org/10.1177/1464884918807056

Ferruci, P. (2019). The End of Ombudsmen? 21st-Century Journalism and Reader Representatives. Journalism \& Mass Communication Quarterly, 96(1), 288-307. https://doi. org/10.1177/1077699018805986

García-Avilés, J.A. (2019). Examining media accountability in online media and the role of active audiences. En T. Eberwein, S. Fengler, \& Karmasin, M. (Eds.), Media accountability in the era of post-truth politics: European challenges and perspectives (pp. 270-283). Londres: Routledge.

Gutiérrez del Álamo, P. (2015). El defensor del lector de El País (1985-2010). Una experiencia pionera en España. Málaga: Universidad de Málaga.

Hallin, D.C., \& Mancini, P. (2004). Comparing media systems: three models of media and politics. Cambridge: Cambridge University Press.

Hameleers, M., \& van der Meer, T. (2019). Misinformation and polarization in a high-choice media environment: How effective are political fact-checkers? Communication Research. Advance online publication. https://doi.org/10.1177/0093650218819671

Hanitzsch, T., Van Dalen, A., \& Steindl, N. (2018). Caught in the Nexus: A Comparative and Longitudinal Analysis of Public Trust in the Press. The International Journal of Press/Politics, 23(1), 3-23. https://doi.org/10.1177/1940161217740695

Harro-Loit, H. (2015). Journalists' views about accountability to different societal groups. Journal of Media Ethics: Exploring Questions of Media Morality, 30(1), 31-43. https://doi.org/10.1080/08 900523.2014 .985296 
Haydon, G. (1978). On being responsible. The Philosophical Quarterly, 28(110), 46-57. https:// doi.org/10.2307/2219043

Higgins Joyce, V., Saldaña, M., Schmitz, A., \& Alves, R.C. (2017). Ethical perspectives in Latin America's journalism community: A comparative analysis of acceptance of controversial practice for investigative reporting. International Communication Gazette, 79(5), 459-482. https://doi. org/10.1177/1748048516688131

Himelboim, I., \& Limor, Y. (2011). Media Institutions, News Organizations, and the Journalistic Social Role Worldwide: A Cross-National and Cross-Organizational Study of Codes of Ethics. Mass Communication \& Society, 14(1), 71-92. https://doi.org/10.1080/15205430903359719

Hodges, L.W. (1986). Defining press responsibility: a functional approach. En D. Elliot (Ed.), Responsible journalism (pp. 13-31). Beverly Hills, California: Sage.

Hutchins, B., \& Boyle, R. (2017). A community of practice: Sport journalism, mobile media and institutional change. Digital Journalism, 5(5), 496-512. https://doi.org/10.1080/21670811.2016.1 234147

Joseph, N. L. (2011). Correcting the record. Journalism Practice, 5(6): 704-718. https://doi.org/1 $0.1080 / 17512786.2011 .587670$

Justel, S., Micó, J.L., \& Ordeix, E. (2018). Governing the Media: Web Analytics in Spanish Newsrooms. Tripodos, 42, 93-106.

Karlsson, M., Clerwall, C., \& Nord, L. (2017). Do not stand corrected. Transparency and users' attitudes to inaccurate news and corrections in online journalism. Journalism \& Mass Communication Quarterly, 94(1), 148-167. https://doi.org/10.1177/1077699016654680

Karmasin, M., Kraus, D., Kaltenbrunner, A., \& Bichler, K. (2014). Media Ethics as Institutional Ethics - the Potential of Corporate Social Responsibility. En S. Fengler, T. Eberwein, G. Mazzoleni, C. Porlezza \& S. Russ-Mohl (Eds.), Journalists and Media Accountability. An International Study of News People in the Digital Age (pp: 231-248). Nueva York: Peter Lang.

Kendall, M., \& Gibbons, J.D. (1990). Rank Correlation Methods. Charles Griffin Book Series (5th ed.). Oxford: Oxford University Press.

King, N., \& Horrocks, C. (2010). Interviews in qualitative research. Thousand Oaks, CA: Sage.

Luengo, M., Maciá-Barber, C., \& Requejo-Alemán, J.L. (2017). Evaluating organisational ethics in Spanish news media. Journalism, 18(9), 1142-1162.

Maciá, C. (2006). La figura del defensor del lector, del oyente y del telespectador. Madrid: Universitas.

Mauri-Ríos, M., \& Ramon, X. (2015). Nuevos sistemas de rendición de cuentas de la información periodística. Una exploración del escenario online español. El Profesional de la Información, 24(4), 380-389. https://doi.org/10.3145/epi.2015.jul.04

Mauri-Ríos, M., Rodríguez-Martínez, R., Figueras-Maz, M., \& Fedele, M. (2018). Press councils as a traditional instrument of media self-regulation: The perceptions of European journalists. Journal of Applied Journalism \& Media Studies, 7(2), 221-243. https://doi.org/10.1386/ ajms.7.2.221_1

Mayes, I. (2004). Trust Me - I'm an ombudsman. British Journalism Review, 15(2), 65-70. https://doi.org/10.1177/0956474804046018 
McQuail, D. (1997). Accountability of media to society. Principles and means. European Journal of Communication, 12(4), 511-529. https://doi.org/10.1177/0267323197012004004

McQuail, D. (2003). Media Accountability and Freedom of Publication. Nueva York: Oxford University Press.

Meltzer, K., \& Martik, E. (2017). Journalists as communities of practice. Journal of Communication Inquiry, 41(3), 207-226. https://doi.org/10.1177/0196859917706158

Neveu, E. (2019). The challenge of thinking ecologically. Journalism, 20(1), 198-201. https://doi. org/10.1177/1464884918808139

Nolan, D., \& Marjoribanks, T. (2011). Public editors and media governance at The Guardian and The New York Times. Journalism Practice, 5(1), 3-17. https://doi.org/10.1080/17512786.2 010.482764

Pastor, L. (2010). Teoría de las cartas al director. La gestión periodística del público. Barcelona: UOC.

Plaisance, P.L. (2000). The concept of media accountability reconsidered. Journal of Mass Media Ethics: Exploring Questions of Media Morality, 15(4), 257-268. https://doi.org/10.1207/ S15327728JMME1504_5

Raeymaeckers, K. (2005). Letters to the Editor: A Feedback Opportunity Turned into a Marketing Tool. European Journal of Communication, 20(2), 199-221. https://doi. org/10.1177/0267323105052298

Ramon, X., Mauri-Ríos, M., \& Alcalá-Anguiano, F. (2016). Transparencia informativa, autorregulación y participación del público. Comunicación y Sociedad, 25, 101-125.

Ramon, X., Billings, A. C., \& Rojas-Torrijos, J. L. (2019). Interviews with Former ESPN Ombudsmen / Public Editors Kelly McBride, Robert Lipsyte, and Jim Brady. International Journal of Sport Communication, 12(1), 28-35. https://doi.org/10.1123/ijsc.2018-0127

Ramon, X., \& Tulloch, C. (2019). Life Beyond Clickbait Journalism: A Transnational Study of the Independent Football Magazine Market. Communication \& Sport. Advance online publication. https://doi.org/10.1177/2167479519878674

Roberts, C. (2012). Identifying and defining values in media codes of ethics. Journal of Mass Media Ethics: Exploring Questions of Media Morality, 27(2), 115-129. https://doi.org/10.1080/08 900523.2012.669289

Rodríguez-Martínez, R., López-Meri, A., Merino-Arribas, A., \& Mauri-Ríos, M. (2017). Instrumentos de rendición de cuentas en España. Análisis comparativo en Cataluña, Galicia, Madrid y Valencia. El Profesional de la Información, 26 (2), 255-266. https://doi.org/10.3145/ epi.2017.mar.12

Rodríguez-Martínez, R., Mauri-Ríos, M., \& Fedele, M. (2017). Criticism as an accountability instrument: the opinion of Spanish journalists. Communication \& Society, 30(1): 57-72. https:// doi.org/10.15581/003.30.1.57-72

Rojas-Torrijos, J. L., \& Ramon, X. (2017). Accountability in social networks. Ever-evolving stylebooks and feedback through Twitter. Revista Latina de Comunicación Social, 72, 915-941. https://doi.org/10.4185/RLCS-2017-1200-50en 
Seoane, M.C., \& Sueiro, S. (2004). Una historia de El País y del Grupo Prisa. De una aventura incierta a una gran industria cultural. Barcelona: Plaza y Janés.

Serazio, M. (2019). The other "fake" news: Professional ideals and objectivity ambitions in brand journalism. Journalism. Advance online publication. https://doi.org/10.1177/1464884919829923

Schmitz, A. (2015). The digital and social media journalist: A comparative analysis of journalists in Argentina, Brazil, Colombia, Mexico, and Peru. The International Communication Gazette, 77(1), 74-101. https://doi.org/10.1177/1748048514556985

Singer, J.B. (2013). The ethical implications of an elite press. Journal of Mass Media Ethics: Exploring Questions of Media Morality, 28(3), 203-216. https://doi.org/10.1080/08900523.2013. 802163

Spiller, R., Degen, M., Kronewald, E., \& Guertler, K. (2016). Media watchblogs as an instrument of media accountability: An international survey. Journal of Applied Journalism \& Media Studies, 5(2), 151-176. https://doi.org/10.1386/ajms.5.2.151_1

Suárez-Villegas, J.C., Zuberogoitia, A., \& Gostín, A. (2019). Instrumentos de rendición de cuentas externos a los medios: los casos de Andalucía y la CAPV. Estudios sobre el Mensaje Periodístico, 25(1), 529-546. https://doi.org/10.5209/ESMP.63744

Torres da Silva, M. (2012). Newsroom practices and letters-to-the-editor. Journalism Practice, 6(2), 250-263. https://doi.org/10.1080/17512786.2011.629124

Traber, M. (1997). Conclusion: an Ethics of communication worthy of human beings. En C. Christians \& M. Traber (Eds.), Communication ethics and universal values (pp. 327-343). Thousand Oaks, California: Sage.

Van Dalen, A., \& Deuze, M. (2006). Readers' advocates or newspapers' ambassadors? European Journal of Communication, 21(4), 457-475. doi: https://doi.org/10.1177/0267323106070011

Van der Wurff, R., \& Schönbach, K. (2014). Audience Expectations of Media Accountability in the Netherlands. Journalism Studies, 15(2), 121-137. https://doi. org/10.1080/1461670X.2013.801679

Wahl-Jorgensen, K. (2002). Understanding the Conditions for Public Discourse: four rules for selecting letters to the editor. Journalism Studies, 3(1), 69-81. https://doi. org/10.1080/14616700120107347

Waisbord, S. (2019). The vulnerabilities of journalism. Journalism, 20(1), 210-213. https://doi. org/10.1177/1464884918809283

Weischenberg, S., Malik, M., \& Scholl, A. (2006). Journalismus in Deutschland. Media Perspektiven, 7, 346-361.

Wilkins, L., \& Brennen, B. (2004). Conflicted interests, contested terrain: journalism ethics codes then and now. Journalism Studies, 5(3), 297-309. https://doi.org/10.1080/1461670042000246061

Zelizer, B. (2018). Epilogue: Timing the study of news temporality. Journalism, 19(1), 111-121. https://doi.org/10.1177/1464884916688964

Zuberogoitia, A., Bidegain, E., \& Gostín, A. (2019). Mapping media accountability in a stateless nation: The case of the Basque Country. Catalan Journal of Communication \& Cultural Studies, 11, 59-78. https://doi.org/10.1386/cjcs.11.1.59_1 